\title{
Ubuntu research values needed for Africa
}

\section{Ex Africa semper aliquid novi.}

Africa's health researchers last month took greater collective responsibility for cultivating their continent's historically neglected and under-funded work when an international forum in Cape Town agreed on co-operative strategies to translate their findings into improving more lives on the ground.

A 3-day forum, facilitated by the Swissbased Council on Health Research for Development (COHRED), and entitled 'Beyond Aid ... Research and Innovation as Key Drivers for Health, Equity and Development,' vowed to improve 'south to south' connections and help persuade African governments of the huge economic value of investing in health research. Members of the World Health Organization's (WHO) African committee also met on the sidelines to explore creating a 'home-grown' inter-disciplinary body to improve research, create platforms and share ideas emerging from the conference and elsewhere.

In a session focusing specifically on human resources for health research in Africa, ${ }^{1}$ Prof. Michael Clarke, Director of Global Health Policy for the Canadian governmentestablished International Development Research Centre (IDRC), said business propositions to national governments for research funding were most often extremely poorly made. What was needed was to turn a 25-page research paper into a '3-pager' for the relevant state scientific research

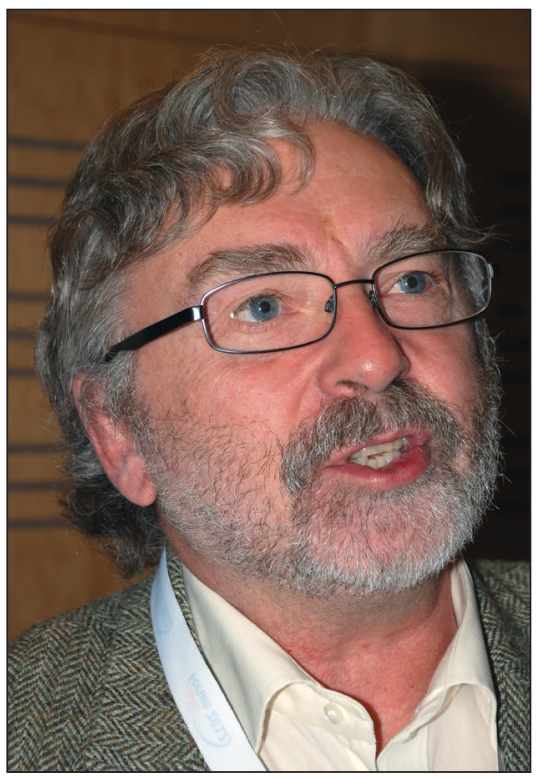

Prof. Michael Clarke, Director: Global Health Policy, IDRC, Canada.

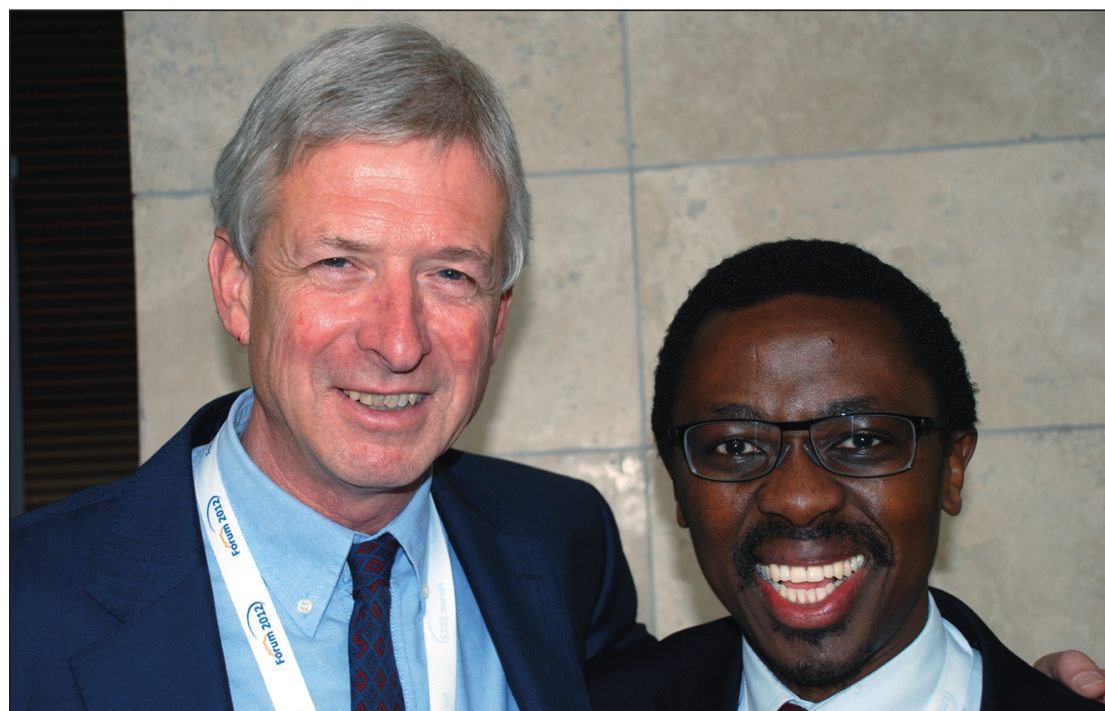

Prof. Carel IJsselmuiden, COHRED Executive Director, and Prof. Bongani Mayosi, Head of the Department of Medicine, UCT.

committee, a '1-pager' for the minister of health and a 'single bullet line' for the finance minister - outlining exactly how much it would save.

He cited one IDRC project probing the link between maternal mortality and morbidity and agricultural output in developing countries (where most farm workers are women). 'When you say, these findings have to go into your overall plan for increasing agricultural output, they sit up and take notice,' he said.

\section{No mechanism to translate research into practice}

Prof. Bongani Mayosi, chairperson of South Africa's National Health Research Committee (NHRC), and Head of the Department of Medicine at the University of Cape Town, said government needed to set an ambitious benchmark for funding research to ensure it was translated into policy, health programmes and clinical practice. 'There's currently no formal mechanism to ensure that the research coming out translates into clinical practice. We're not doing too well on the Millennium Development Goals and we're not using evidence and translating it into quality - in fact there's been a disinvestment from clinical research. We need to hold our governments to account so that we go beyond (foreign) aid.'

He saw the conference as 'connecting people from industry, academia, policy makers and those from the rich north, plus the developing countries to boost research and development and innovation'. Mayosi said the biggest challenge was overcoming the separation between research activity and its impact on society. 'We're not seeing better outcomes in patients and we're not (sufficiently) converting research into products and processes.' Asked to give a concrete local example, he cited work being done by his department on improving notoriously difficult tuberculosis (TB) diagnoses. 'We've known for about 10 years that in people with $\mathrm{TB}$, certain biochemical markers are very high (e.g. interferon-gamma); we're trying to develop a simple dipstick test for TB using

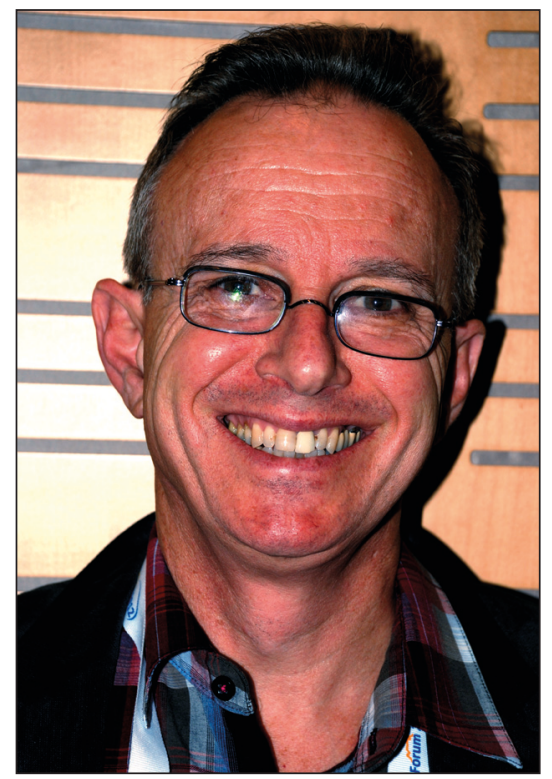

Prof. Eric Buch, Dean: Faculty of Health Sciences, University of Pretoria. 
this knowledge. What happens is that people simply report something and then walk to the next paper (without actually making a difference to patients).'

Prof. Eric Buch, Dean of the Faculty of Health Sciences at the University of Pretoria and a former health advisor to the New Partnership for Africa's Development (NEPAD), said that in spite of some 20 significant capacity-building initiatives in Africa, there was little intersectoral work to build collaboration between countries. 'We need to root much deeper and wider into the whole development discourse on Africa; there are very few clear targets that say if we want human resources for health research in Africa, this is what we need to have achieved in the next five years. It's like if I was in NEPAD's headquarters in Johannesburg and wanted to drive the 600 kilometers to Maputo and said we need to raise R100 for petrol. You have to begin with a concrete action plan, specifics on who and how. So many African Union summits talk in broad generalities. You have to say what in concrete terms each of the players will deliver in order to get to your five-year targets. Funding and retention and reward systems are absolutely critical. If you don't stop the bleeding you won't sort out the patient. Very often in Africa the patient bleeds to death. We must stop the brain drain and the response has to cut across ministries, he added.

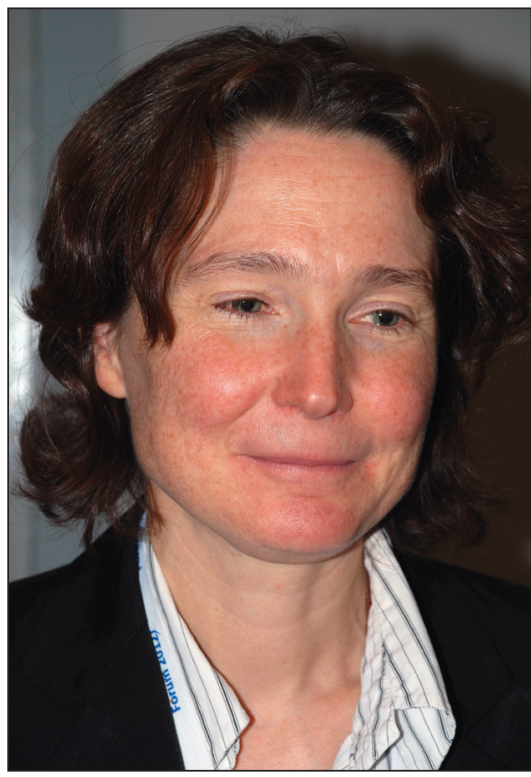

Val Snewin, International Activities Manager, Wellcome Trust, United Kingdom.

Wellcome Trust - 'funds follow co-ordinated research'

Val Snewin, International Activities Manager for the Wellcome Trust in the
UK, said her employer funded some 50 different African universities and research institutions with a key aim of capacity strengthening and enabling 'south to south' partnerships. Using the networking model, they hoped to improve financial reporting and research management and were using a 'real time' programme to see where each of these consortia got to in five years so they could share learning. 'We need sustainable, independent, robust and transparent national health research funding entities with a regional role and influence so that other funders can learn and support human resources for health research initiatives. We'd like to know who to ask; not just the usual three ministries (health, science and technology and finance).' She said an overall strategy for Africa was 'a bit like reaching for the moon; but individual countries with stakeholder buy-in will make it much easier for us'. The Wellcome Trust was currently mapping where all their funding went and it would shortly be possible to use Google Earth to see a snapshot of this. They had also just completed a study on the true cost of doing research in middle- and lower-income countries - which could prove invaluable to delegates seeking funding from their governments.

\section{He cited one IDRC project probing the link between maternal mortality and morbidity and agricultural output in developing countries (where most farm workers are women). 'When you say, these findings have to go into your overall plan for increasing agricultural output, they sit up and take notice,' he said.}

One robust major funder that has emerged virtually unscathed from the global economic downturn, the Global Alliance for Vaccines and Immunization (GAVI), came in for some stick from a global health development specialist, Irish Aid's Dairmuid McClean. He singled out GAVI and 'cash magnet' research institutions (like Uganda's Makerere University), for not 'stepping up' to their global governmental responsibilities and leadership. McClean said GAVI needed to support 'other bits and pieces' (i.e. research bodies) besides the 'darling institutions' in order to enable them to function at adequate levels so that immunisation could be more effective. 'It's the usual suspects and culprits that win funding (like the highly effective Makerere University). That is not

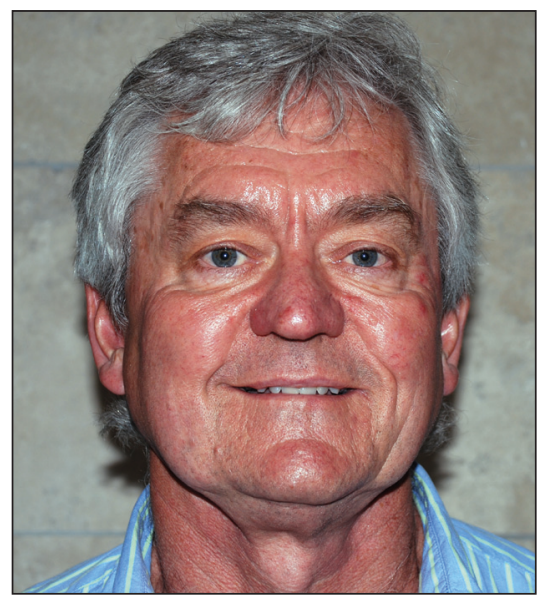

Dairmuid McClean, global health development specialist with Irish Aid.

to 'dis(respect)' or undervalue them, but they always get the research money. More partnership is needed with the less popular but equally important institutions', he said.

Prof. Nelson Sewankamba, Principal of Makerere University, said his campus's expertise and capacity enabled it to win funding and that it was actually a shining example' of regional research collaboration. $\mathrm{He}$ cited several collaborative projects, including a centre for child wellness in Malawi, a 3-year partnership with the University of Abuja in Nigeria and projects with the Kilimanjaro Christian National Medical College and the National Institute of Medical Research in Tanzania, among others. 'However, his (McClean's) statement is broadly correct. Many institutions that are better-off than others are not collaborating as much as they should. It should be happening much more.'

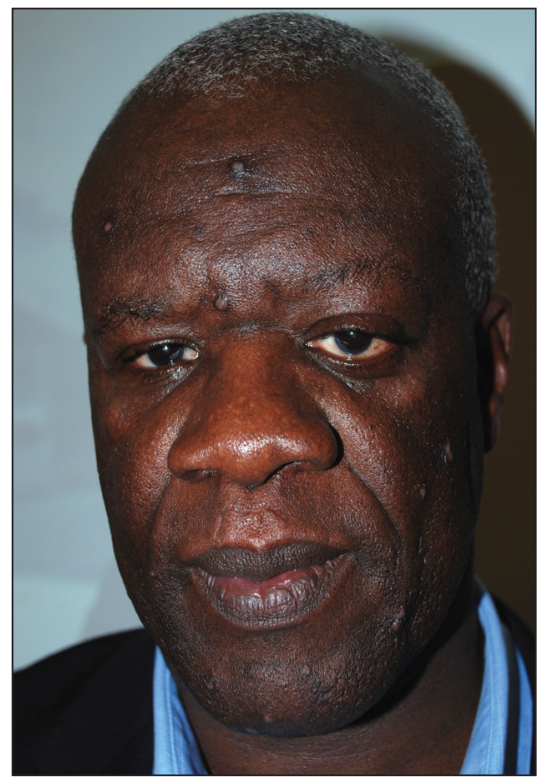

Prof. Nelson Sewankamba, Principal, Makarere University, Uganda. 
Funding and retention and reward systems are absolutely critical. If you don't stop the bleeding you won't sort out the patient. Very often in Africa the patient bleeds to death. We must stop the brain drain and the response has to cut across ministries, he added.

Dr Samson Kinyanjui, a researcher with the Kenya Medical Research Institute, said the major lessons from the Cape Town waterfront conference were the importance of bringing health research to the top of continental and government agendas, recognising the need for a comprehensive approach to capacity building and adopting a strategic systemic approach 'with clear measurable outputs at the end. Within that there should be a framework on how to attract people, train them and retain

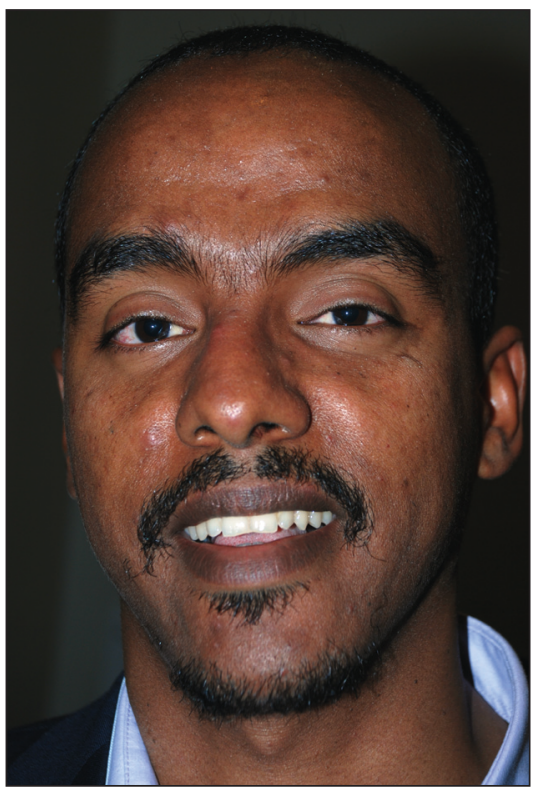

Dr Samson Kinyanjui, researcher, Kenya Medical Research Institute. them. Research is an international issue; the question is not whether or not to have international funding but how to have equitable partnerships. Address the power dynamics within that situation. And that can only happen if people feel empowered, have the capacity and training and can speak as equals.'

$\mathrm{He}$ said the biggest human attrition in research came between $\mathrm{PhD}$ and postdoctorate level when $80 \%$ of people were lost - a problem in developed countries but a real crisis in developing ones where the human resource pool was much smaller.

\section{Chris Bateman}

chrisb@hmpg.co.za

1. IJsselmuiden J, Marais DL, Becerra-Posada F, Ghannem H. Africa's neglected area of human resources for health research the way forward. S Afr Med J 2012;102(4):228-232. 